\title{
Fetal and postnatal ovine mesenteric vascular reactivity
}

\author{
Jayasree Nair', Sylvia F. Gugino' ', Lori C. Nielsen' ${ }^{1}$, Michael G. Caty ${ }^{2}$ and Satyan Lakshminrusimha'
}

BACKGROUND: Intestinal circulation and mesenteric arterial (MA) reactivity may play a role in preparing the fetus for enteral nutrition. We hypothesized that MA vasoreactivity changes with gestation and vasodilator pathways predominate in the postnatal period.

METHODS: Small distal MA rings (0.5-mm diameter) were isolated from fetal (116-d, 128-d, 134-d, and 141-d gestation, term $\sim 147$ d) and postnatal lambs. Vasoreactivity was evaluated using vasoconstrictors (norepinephrine (NE) after pretreatment with propranolol and endothelin-1(ET-1)) and vasodilators (NO donors A23187 and s-nitrosopenicillamine (SNAP)). Protein and mRNA assays for receptors and enzymes (endothelin receptor A, alpha-adrenergic receptor 1A (ADRA1A), endothelial NO synthase (eNOS), soluble guanylyl cyclase (sGC), and phosphodiesterase5 (PDE5)) were performed in mesenteric arteries.

RESULTS: MA constriction to NE and ET-1 peaked at $134 \mathrm{~d}$. Relaxation to A23187 and SNAP was maximal after birth. Basal eNOS activity was low at $134 \mathrm{~d}$. ADRA1A mRNA and protein increased significantly at $134 \mathrm{~d}$ and decreased postnatally. SGC and PDE5 protein increased from 134 to $141 \mathrm{~d}$.

CONCLUSION: Mesenteric vasoconstriction predominates in late-preterm gestation (134 d; the postconceptional age with the highest incidence of necrotizing enterocolitis (NEC)) followed by a conversion to vasodilatory influences near the time of full-term birth. Perturbations in this ontogenic mechanism, including preterm birth, may be a risk factor for NEC.

$\mathbf{T}$ he gastrointestinal tract is continuously exposed to swallowed amniotic fluid throughout fetal life. After birth, a more complex substrate (maternal breast milk or formula) is presented to the neonatal gut for digestion and absorption. Mesenteric arteries play an important role in this process, regulating intestinal circulation by mediating postprandial hyperemia (1), potentially increasing nutrient absorption and meeting gut metabolic needs.

Catecholamines and endothelin are important vasoconstrictors, and nitric oxide (NO) is the main vasodilator of mesenteric vasculature (2). An optimal balance between mesenteric vasoconstrictor and dilator forces is required to meet postnatal metabolic demands, and any imbalance may contribute to an increase in propensity for intestinal ischemia and predispose preterm infants to necrotizing enterocolitis (NEC) (2), a major cause of morbidity and mortality among preterm infants (3). While prematurity remains the primary risk factor for development of NEC, the presence of a feeding insult, abnormal bacterial flora, and intestinal ischemia/reperfusion injury with activation of pro-inflammatory cytokines contribute to the etiology of NEC in preterm infants. A temporal association between packed red blood cell transfusion and NEC has been reported $(4,5)$. Packed red blood cell transfusion has also been shown to increase mesenteric arterial (MA) contractility in preterm fed lambs (6). NO is thought to play a key role as a molecular signaling "hub" in the generation of gut barrier failure in NEC (7) as well as in the pathogenesis of transfusion-associated gut injury (8).

Regulation of fetal and postnatal mesenteric circulation by vasoactive mediators has been evaluated in piglets. The role of $\mathrm{NO}$ in regulation of porcine postnatal intestinal circulation has been found to be age specific, being more substantial in 3-d-old than in 35-d-old piglets (9). Reber et al. (10) demonstrated increased endothelial nitric oxide synthase (eNOS) protein in mesenteric arteries of 1-d-old fed piglets compared with fetal and 1-d-old unfed piglets. Moonen and Villamor (11) studied fetal and postnatal mesenteric vascular reactivity in chicks and concluded that maturation of vasodilator mechanisms precedes that of vasoconstrictor mechanisms. This study adds to the current knowledge of ontogeny of mesenteric vasoreactivity using a large mammalian (ovine) fetal model at various gestational age (GA) time points. Evaluating normal physiologic changes in fetal and neonatal mesenteric circulation may enhance our understanding of pathophysiology of NEC.

The objective of this study was to evaluate the developmental changes in mesenteric vascular reactivity in fetal lambs of various GAs. We evaluated the contractile response of ovine mesenteric arteries to constrictor agents-receptor-mediated agents such as norepinephrine (NE) and endothelin-1 (ET1) and receptor-independent constrictor, potassium chloride $(\mathrm{KCl})$ - and relaxation response to $\mathrm{NO}$ donors. We further measured changes in the expression of receptors and enzymes during the last trimester and after birth and feeds. We hypothesized that MA vasoreactivity changes with GA and vasodilator

'Department of Pediatrics, University at Buffalo, Buffalo, New York; ${ }^{2}$ Department of Surgery, Yale New Haven Children's Hospital, New Haven, Connecticut. Correspondence: Jayasree Nair (jnair@upa.chob.edu)

Received 15 July 2015; accepted 24 September 2015; advance online publication 20 January 2016. doi:10.1038/pr.2015.260 
pathways predominate close to full-term birth and during the postnatal period.

\section{RESULTS}

Mesenteric arteries were isolated from 26 fetal lambs (term gestation $~ 147 \mathrm{~d})$ : 116 -d GA $(n=8), 128$-d GA $(n=4)$, 134-d GA $(n=7), 141-d$ GA $(n=7)$, and five postnatal fed lambs.

\section{Ontogeny of Mesenteric Arterial Constriction}

All MA rings constricted in a concentration-dependent manner to NE and ET-1. Mesenteric arteries isolated from 116-d GA lambs showed a low constriction response to NE, ET-1, and $\mathrm{KCl}$, suggesting decreased inherent vasoconstriction capacity at this premature gestation. Mesenteric arterial rings isolated from 134- and 141-d GA lambs constricted significantly better to NE (Figure 1a), ET-1 (Figure 1b), and $\mathrm{KCl}$ (Figure 1c). Mesenteric arteries isolated from postnatal lambs showed reduced constriction to NE and ET-1 as compared with fetal arterial rings (Figure 1a,b). Mesenteric arterial constriction to receptor-independent $\mathrm{KCl}$ was similar at $128-\mathrm{d}$, 134-d, 141-d GA fetal and postnatal lambs (Figure 1c). These findings suggest that the differences noted in NE- and ET-1mediated constriction responses at these GAs are probably related to changes in the adrenergic and endothelin receptor density or downstream pathways and not due to changes in inherent constrictor capacity of the MA ring (Figure 1c).
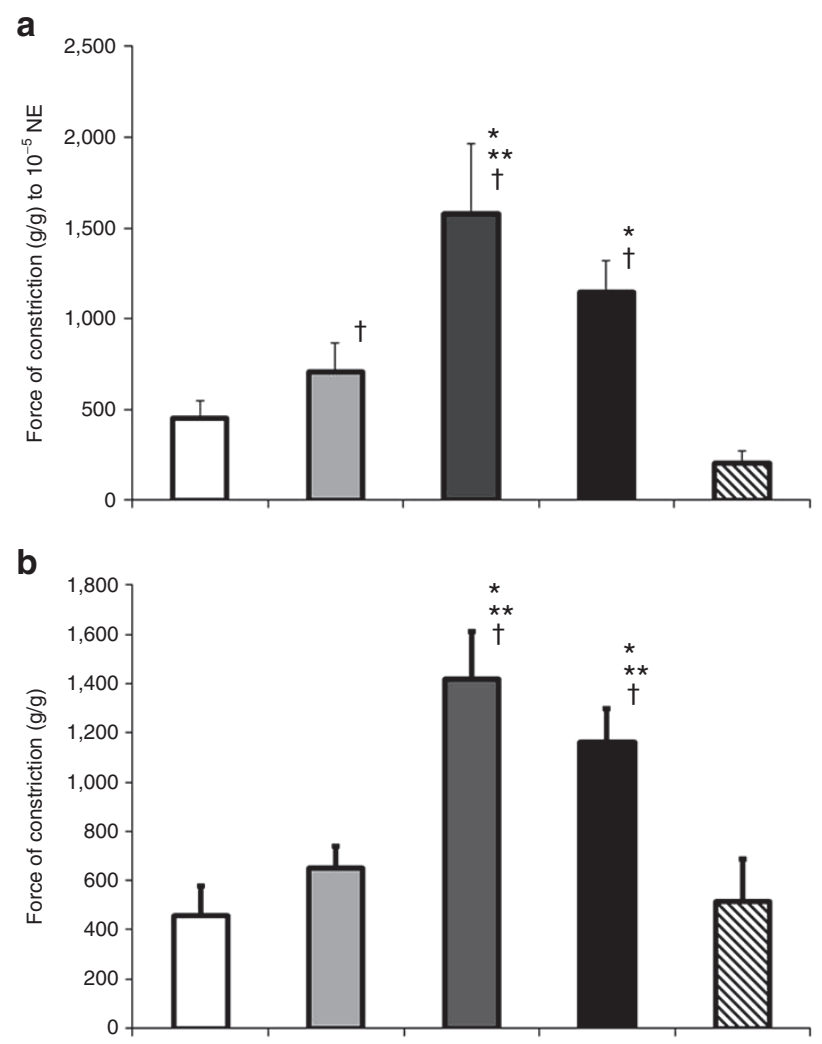

\section{Increase in Contractility in Response to NOS Inhibition}

For evaluating baseline NOS activity, we estimated the increase in constriction response to NE following pretreatment with L-nitro arginine (LNA, $10^{-3} \mathrm{M}$ ), a NOS antagonist. The results are reported as percentage increase over NE constriction $\left(10^{-5} \mathrm{M}\right)$ alone ((constriction with LNA + NE $10^{-5} \mathrm{M}-$ constriction with NE $10^{-5} \mathrm{M}$ alone $) \times 100 \div$ constriction with NE $10^{-5} \mathrm{M}$ alone). All paired samples showed an increase in LNA constriction response, reflecting baseline NOS activity (Figure 1d). Although no significant differences were noted across GAs, the increase in LNA-mediated contraction was minimal in mesenteric arteries isolated from 134-d GA lambs suggesting minimal baseline NOS activity at this gestation.

\section{Ontogeny of Mesenteric Arterial Relaxation}

Mesenteric arterial rings from 116- and 128-d GA lambs relaxed poorly to A23187, suggesting reduced endotheliumdependent relaxation. Relaxation to A23187 increased by 134-d gestation similar to that observed in 141-d GA and postnatal lambs (Figure 2a). The relaxation response to an endothelium-independent NO donor, s-nitrosopenicillamine (SNAP), was gestation dependent and improved by late gestation. Relaxation to SNAP markedly increased in the postnatal group (Figure $2 \mathrm{~b}$ ). This suggests that the mesenteric vascular endothelium is primed to endothelium-dependent relaxation

C

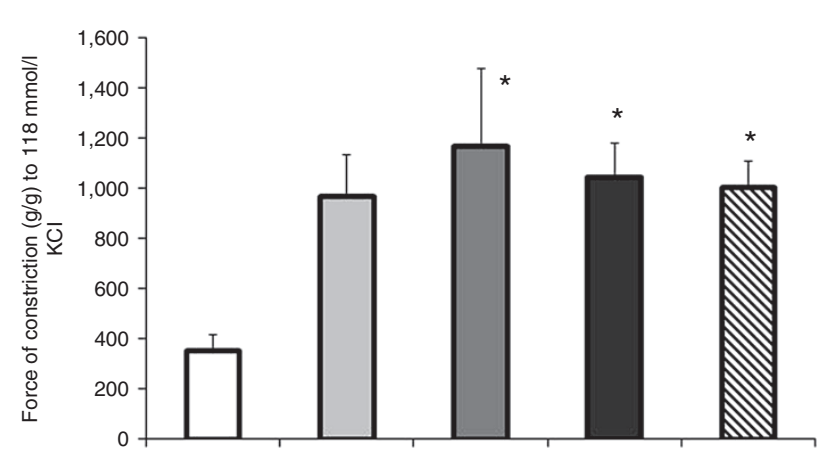

d

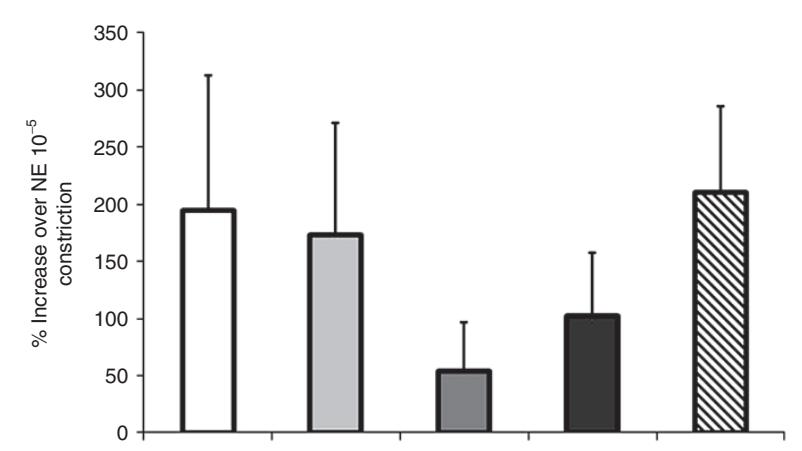

Figure 1. Constriction response of ovine mesenteric arteries. (a) Constriction to norepinephrine (NE)_ovine mesenteric arterial (MA) constriction responses to NE $10^{-5}$ and (b) constriction to endothelin-1 10 10 (c) Constriction to $\mathrm{KCl}$-ovine MA constriction response to $118 \mathrm{mM} \mathrm{KCl}$. (d) Response to L-nitro arginine (LNA) -enhancement of NE induced constriction response by pretreatment with $10^{-3} \mathrm{LNA}$. $P<0.05$ vs. $116 \mathrm{~d}$ by Fisher's protected least significant difference (PLSD). * $P<0.05$ vs. 116-d fetus by Fisher's PLSD. White bars, 116-d fetus; light gray bars, 128-d fetus; dark gray bars, 134- $d$ fetus; black bars, $141-d$ fetus; and hatched bars, postnatal. ${ }^{* *} P<0.05$ vs. $128-d$ fetus by Fisher's PLSD. ${ }^{\dagger} P<0.05$ vs. postnatal by Fisher's PLSD. 

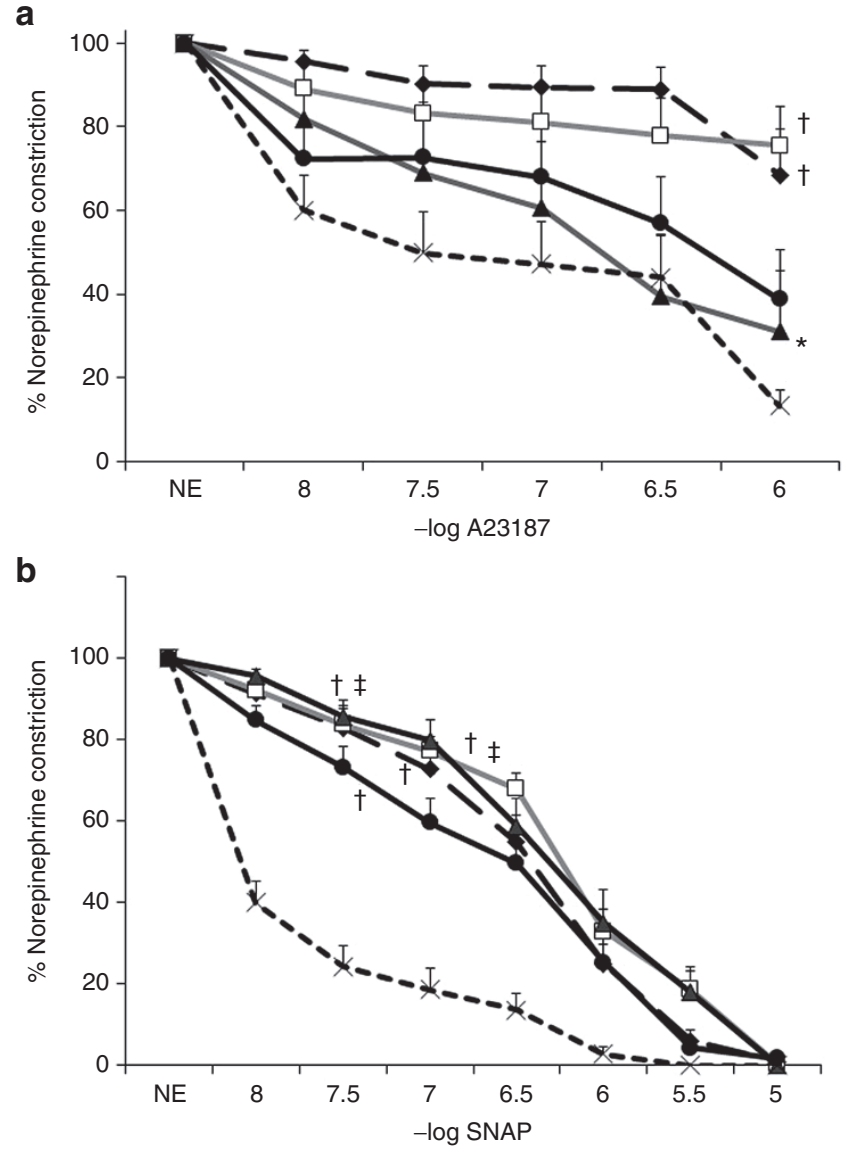

Figure 2. Relaxation response of ovine mesenteric arteries to nitric oxide donors. (a) A23187-ontogeny of preterm ovine mesenteric arterial relaxation response to nitric oxide donor $\mathrm{A} 23187$ and (b) s-nitrosopenicillamine (SNAP). $\bullet, 116-d$ fetus; $\square, 128-d$ fetus; $\mathbf{\Lambda}, 134-d$ fetus; $\bullet$, 141 -d fetus; and $x$, postnatal. ${ }^{*} P<0.05$ vs. $116-d$ fetus by ANOVA repeated measures. ${ }^{+} P<0.05$ vs. postnatal by ANOVA repeated measures. ${ }^{\ddagger} P<0.05$ vs. $141-\mathrm{d}$ fetus by ANOVA repeated measures. NE, norepinephrine.

by late-preterm gestation. In contrast, MA smooth muscle exhibits maximal relaxation to $\mathrm{NO}$ in later gestation and after birth, in preparation for and in response to postnatal changes including enteral feeds.

\section{mRNA and Protein Assays}

1. Receptors of constrictors: Results from QRTPCR mRNA analysis for alpha-adrenergic receptor 1A (ADRA1A) and endothelin receptor A (ETRA) were plotted as fold change in comparison with the postnatal group (Figure 3a). There was no significant difference in ETRA mRNA, however, ETRA protein was lower at 128 and $141 \mathrm{~d}$ as compared with postnatal group (Figure 3a,b). ADR1A mRNA was significantly higher in the 134-d group as compared with 141-d and postnatal mesenteric arteries (Figure 3a). There was a statistically significant pattern noted in ADRA1A protein ontogeny. ADRA1A protein rose significantly from 128 - to 134 -d gestation, remained high at $141 \mathrm{~d}$ gestation, and decreased after birth (Figure 3b).
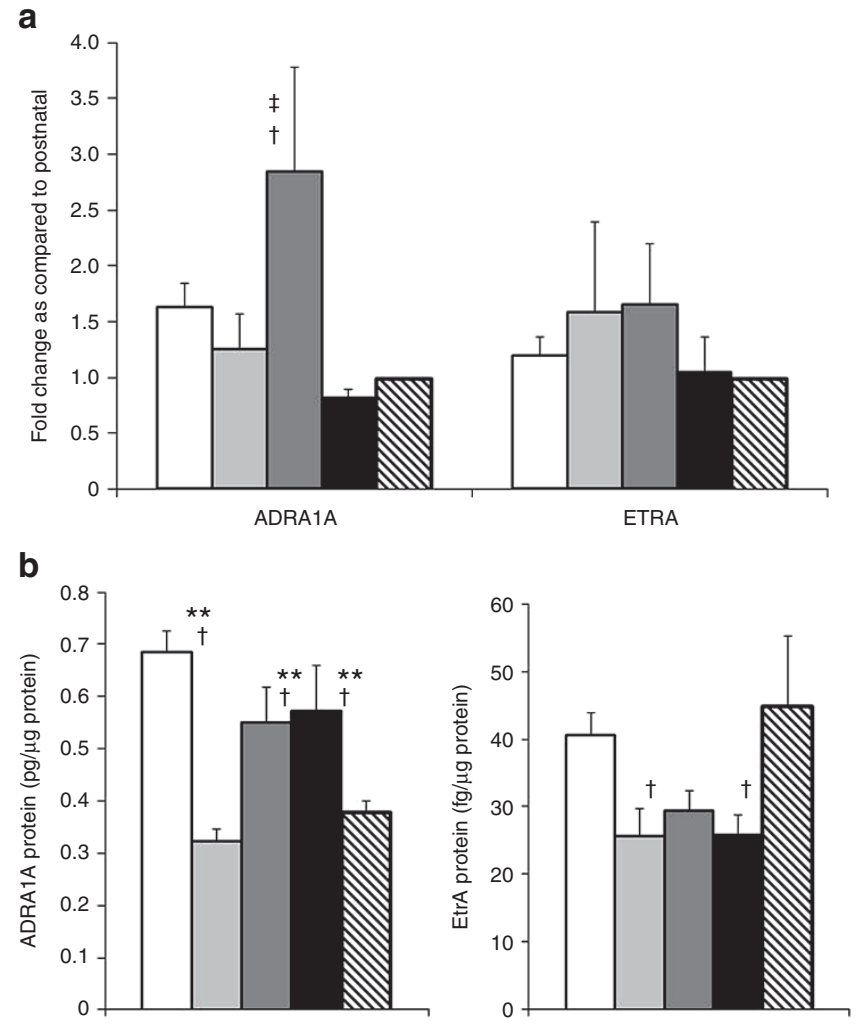

Figure 3. Changes in mRNA and protein expression for constrictor pathway. (a) QRTPCR mRNA analysis of constrictors: real-time PCR assays for alpha-adrenergic receptor $1 A(A D R A 1 A)$ and endothelin receptor $A$ (ETRA) plotted as fold change compared with postnatal ovine mesenteric arteries. (b). Quantitative protein assay by enzyme-linked immunosorbent assay of constrictors-ADRA $1 A$ and ETRA. ${ }^{*} P<0.05$ vs. 116 -d fetus (white bars). ${ }^{* *} P<0.05$ vs. 128 -d fetus (light gray bars), ${ }^{\ddagger} P<0.05$ vs. 141 -d fetus (black bars), ${ }^{+} P<0.05$ vs. postnatal (hatched bars) by Fisher's protected least significant difference. 134-d group is represented by dark gray bars.

2. NO pathway enzymes: eNOS mRNA remained abundant during fetal period and decreased significantly in the postnatal group as compared with 116-d and 134-d fetal groups (Figure 4a). No significant differences were noted in sGC mRNA PCR across the GA group (Figure 4c). However, phosphodiesterase5 (PDE5) mRNA was significantly higher in 128-d group compared with 116-d fetus. Western blot analysis for eNOS, sGC, and PDE5 protein was performed and the results were normalized to corresponding actin. eNOS protein was significantly lower at $116 \mathrm{~d}$ and increased with GA, peaking at near-term gestation. High MA eNOS protein levels persisted after birth (Figure 4b). sGC protein levels peaked at near-term gestation in fetal mesenteric arteries. PDE5 protein increased with GA with a significant increase noted in postnatal ovine mesenteric arteries (Figure $4 \mathbf{d}$ ).

In summary, there is a distinct developmental ontogeny noted in protein expression of enzymes of the NO pathway. As they near term, eNOS, sGC, and PDE5 proteins increase in preparation for birth and postnatal adaptation. 
a

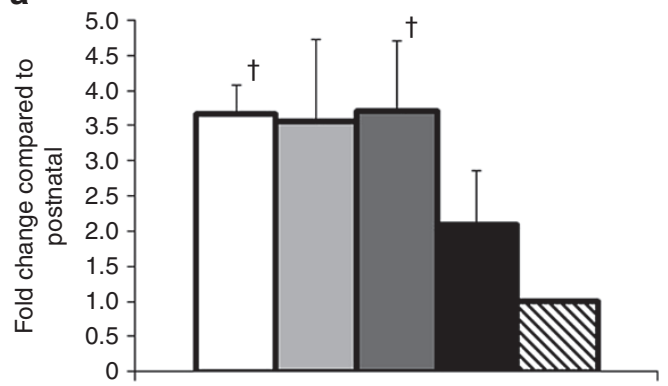

c

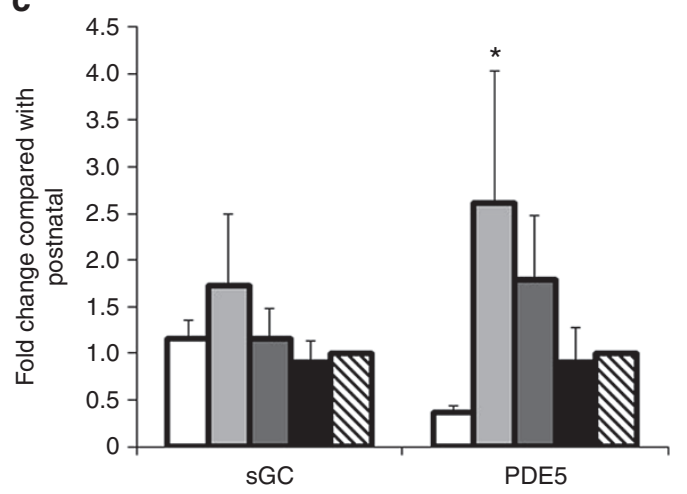

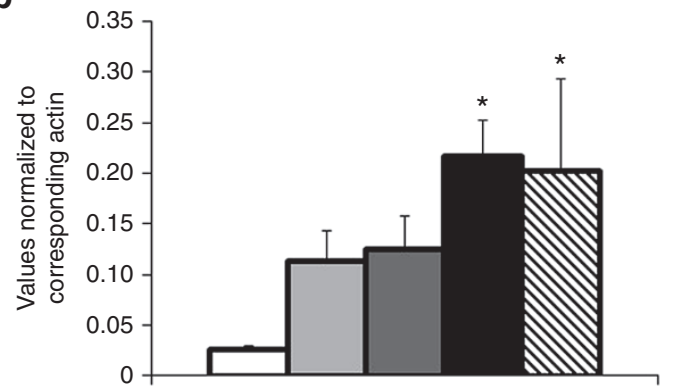

d

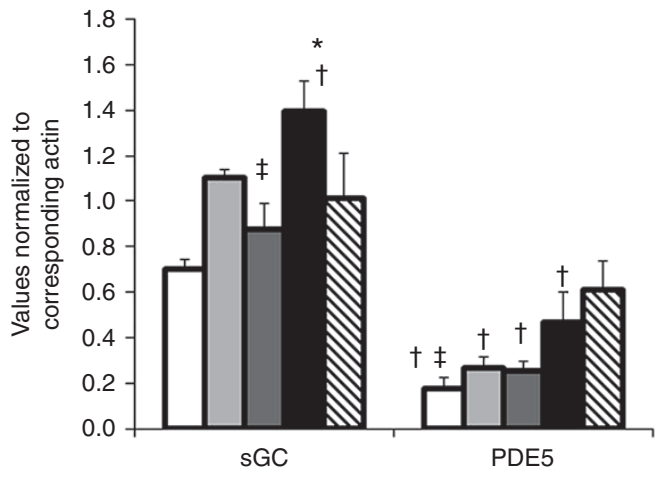

Figure 4. Changes in mRNA and protein expression of enzymes belonging to the NO pathway. (a) QRTPCR and (b) western blot analysis of endothelial NO synthase. (c) QRTPCR and (d) western blot analysis of soluble guanylyl cyclase (sGC) and phosphodiesterase5 (PDE5). QRTPCR results plotted as fold change compared with postnatal (hatched bars) ovine mesenteric arteries. Western blot results depicted as values normalized to corresponding actin. ${ }^{*} P<0.05$ vs. 116 -d fetus (white bars), ${ }^{* *} P<0.05$ vs. 128 - $d$ fetus (light gray bars), ${ }^{\dagger} P<0.05$ vs. postnatal, ${ }^{\ddagger} P<0.05$ vs. $141-d$ fetus (black) by Fisher's protected least significant difference. 134- $\mathrm{d}$ group is represented by dark gray bars.

\section{DISCUSSION}

The mesenteric circulation plays an important role during fetal life in preparing the gastrointestinal tract from a relatively dormant organ absorbing amniotic fluid to an active site of nutrient absorption during postnatal life. Intestinal oxygen uptake and blood flow increase dramatically after birth to sustain rapid growth of the mucosa and oxidative demands of enteral nutrition (12). Another unique aspect of postnatal splanchnic circulation is its ability to increase blood flow $30-130 \%$ after a meal (postprandial hyperemia) (12-14). However, very little information is available on changes in mesenteric vasoreactivity and vasoactive mediators with gestation that enable postnatal and postprandial increase in intestinal blood flow.

In this study, we demonstrate that intrinsic properties of the ovine intestinal vasculature change with GA. The GA corresponding to human fetuses is based on respiratory embryology and physiology in fetal lambs (15-18). The GA of $134 \mathrm{~d}$ is equated to 34 -wk postmenstrual age in humans as pulmonary development is delayed in sheep compared with humans (15). Late-preterm gestation is considered to be the end of the saccular stage of lung development. The exact pattern of gastrointestinal maturation in lambs is not known, but data on intestinal motility indicate that it may be delayed as compared with humans similar to maturation of the respiratory system. Large farm animals such as pig and sheep have been used to study gut maturity due to their large body size. As described by Sangild et al. (19), $88-95 \%$ gestation in these species is associated with degrees of gastrointestinal immaturity similar to those in infants born at $70-90 \%$ gestation. A comparison of fasting small intestinal motor activity in preterm infants and sheep observed low grade activity seen in infants of under 30 -wk gestation similar to the disorganized spiking activity observed in sheep from $0.6-0.8$ of term $(20,21)$.

The newborn intestinal vascular resistance is maintained by a dynamic balance between constrictor (mediated by ET- 1 and catecholamines) and dilator stimuli (mediated by NO). Under steady-state conditions in the postnatal period, the balance favors vasodilation secondary to the abundant production of endothelium-derived NO (2). In our isolated vessel studies, we used NE and ET-1 as the constricting agents. NE induces vasoconstriction by its action on alpha-adrenergic receptors. Although there are multiple alpha-adrenergic receptors identified, previous studies in rat, dog, and humans show that ADRA1A predominates in the mesenteric circulation (22-24). ET-1, produced by endothelial cells, is a potent vasoconstrictor peptide that plays an important role in the maintenance of basal vasomotor tone (25), especially in the intestinal circulation (26). It acts through two receptors A and B (ETRA and ETRB). Under resting conditions, the force of ETRA-induced vasoconstriction exceeds that of ETRB-generated vasodilation, with the net effect being vasoconstriction (2).

At early gestation (116d), mesenteric arteries constrict poorly to NE, ET-1, and $\mathrm{KCl}$ (Figure 1) in spite of adequate levels of receptor protein (Figure $3 \mathbf{b}$ ). This gestation corresponds to a 


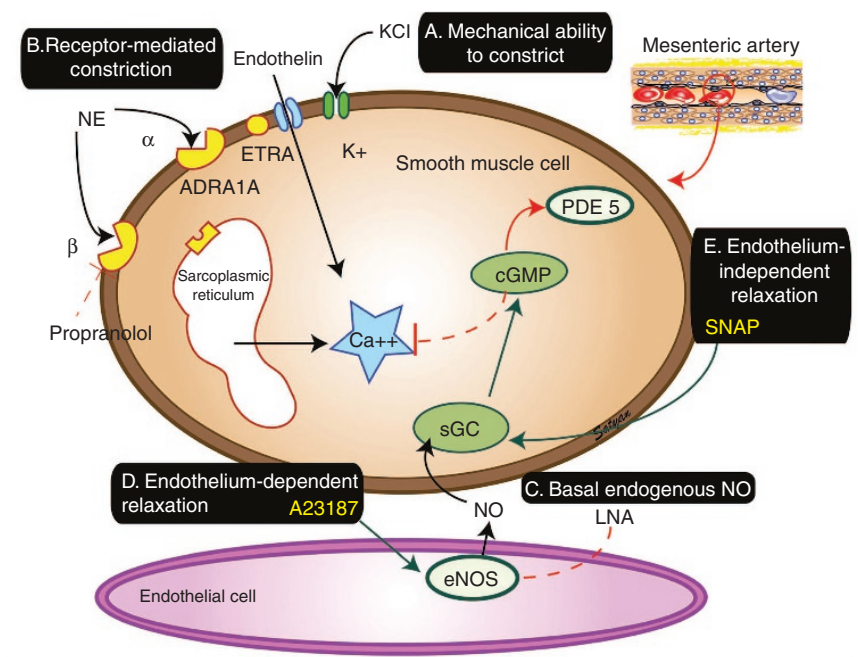

\begin{tabular}{|c|c|c|c|c|c|c|c|}
\hline & Properties assessed & Agent & \multicolumn{5}{|c|}{ Gestational age (term 147 d) } \\
\cline { 5 - 8 } & & $\mathrm{KCl}$ & $116 \mathrm{~d}$ & $128 \mathrm{~d}$ & $134 \mathrm{~d}$ & $141 \mathrm{~d}$ & Postnatal (fed) \\
\hline A. & $\begin{array}{c}\text { Smooth muscle peak } \\
\text { contractility }\end{array}$ & $\mathrm{KCl}$ & + & +++ & +++ & +++ & +++ \\
\hline $\mathrm{B}$. & $\begin{array}{c}\text { Receptor-mediated } \\
\text { constriction }\end{array}$ & NE and ET-1 & + & + & ++++ & ++++ & + \\
\hline C. & $\begin{array}{c}\text { Basal NO release- } \\
\text { endogenous }\end{array}$ & LNA & ++ & ++ & + & ++ & ++ \\
\hline D. & $\begin{array}{c}\text { Endothelium-dependent } \\
\text { relaxation (eNOS activity) }\end{array}$ & A23187 & + & + & ++ & ++ & ++ \\
\hline E. & $\begin{array}{c}\text { Endothelium independent } \\
\text { relaxation (sGC activity) }\end{array}$ & SNAP & + & + & + & + & +++ \\
\hline
\end{tabular}

Figure 5. Summary of the vasoconstrictor and vasorelaxant properties assessed in the study tabulated based on GA. Figure shows the site of action of the various chemical mediators used to assess each specific response. ADRA1A, alpha-adrenergic receptor $1 A$; eNOS, endothelial NO synthase; ET-1, endothelin-1; ETRA, endothelin receptor A; LNA, L-nitro arginine; $\mathrm{NE}$, norepinephrine; PDE5, phosphodiesterase5; sGC, soluble guanylyl cyclase; SNAP, s-nitrosopenicillamine.

previable state from a lung maturation perspective (16). This pattern suggests poor contractile capacity to receptor-dependent and receptor-independent constrictors at an extremely immature gestation (Figure 5). However, the vasodilator NO pathways appear to be functional at this gestation (Figure 2). Similarly, NO-dependent basal intestinal flow has been demonstrated in vivo in 92- to 100-d GA ovine fetuses (27).

At 128-d (early preterm) gestation, the constriction response to NE and ET-1 remained low with marginal increase compared with 116-d gestation (Figure 1). However, KClinduced constriction increased from $355 \pm 60 \mathrm{~g} / \mathrm{g}$ at 116 - $\mathrm{d}$ GA to $969 \pm 167 \mathrm{~g} / \mathrm{g}$ at 128 -d GA $(P=0.08)$. This suggests that although the inherent contractility of MA smooth muscle cell is increasing at early preterm gestation, low receptor levels (Figure $3 \mathrm{~b}$ ) result in low constriction. No significant changes were observed with NO-mediated vasodilation at this GA although the sGC protein increased significantly in mesenteric arteries (Figure 4d). This period also corresponds to rapid increase in intestinal blood flow. In vivo studies showed a substantial increase in small intestinal blood flow from $127 \pm 11$ to $176 \pm 11 \mathrm{ml} / \mathrm{kg} / \mathrm{min} / 100 \mathrm{~g}$ from 92 - to 100 -d gestation to 128 to 139 -d gestation in lambs $(27,28)$.

At 134-d (late preterm) gestation, significant increase in contractility to NE, ET-1, and $\mathrm{KCl}$ is observed with a significant increase in alpha-adrenergic receptor mRNA and protein levels. Simultaneously, there is a decrease in basal NOS activity with no increase in eNOS protein. Infusion of LNA to fetal lambs results in approximately $40 \%$ decrease in small intestinal blood flow in late gestation lambs compared with approximately $57 \%$ decrease (by $73 \mathrm{ml} / \mathrm{kg} / \mathrm{min} / 100 \mathrm{~g}$ ) in mid-gestation lambs also suggesting lower basal NOS activity at late gestation $(27,28)$. This late-preterm GA is associated with the highest imbalance between mediators of constriction and relaxation favoring the former. Interestingly, this postmenstrual age (32$33 \mathrm{wk}$ corrected GA in extremely preterm infants) is associated with highest incidence of NEC in preterm infants (29-31). Some studies have suggested that a unique factor predisposes preterm infants to develop NEC at this postmenstrual age (2). Increased vasoconstrictor propensity of the mesenteric circulation could be a contributory factor to this predisposition.

The constriction responses to NE, ET-1, and $\mathrm{KCl}$ remain high at 141-d gestation (Figure 1). However, the relaxation pathways are well established and primed with increased levels of eNOS and sGC protein (Figure $3 \mathbf{b}$ ) and improved relaxation response to stimulation of these enzymes (Figure 2). These changes prepare the mesenteric circulation for postnatal life when rapid increase in intestinal blood flow is required to establish intestines as the organ of digestion and absorption of nutrients.

During postnatal period, after introduction of feeds, the balance tips in favor of vasorelaxation. Although the inherent smooth muscle cell capacity to constrict to $\mathrm{KCl}$ is high in the mesenteric arteries, receptor-mediated constriction to NE and ET-1 are markedly diminished (Figure 1). Basal NOS activity is high, and endothelium-dependent (A23187) as well as endothelium-independent (SNAP) relaxation is markedly increased. These changes enable the mesenteric circulation to handle postprandial hyperemia required to digest and absorb nutrients following intermittent feeds.

In a study looking at developmental expression of eNOS in postnatal swine mesenteric arteries, Reber et al. (10) noted that mRNA remained abundant in fetal, postnatal unfed, and postnatal fed groups. The eNOS protein expression, however, was greater in 1-d-old fed swine compared with fetal or 1-d-old nonfed animals. We observed similar results in our study, with abundant eNOS mRNA isolated in fetal mesenteric arteries. Though the eNOS protein assays reflected high levels close to term gestation and postnatally, we did not observe any significant rise in the postnatal group.

sGC ontogeny has not been previously studied in mesenteric arteries. Our data show that although sGC mRNA expression did not change with GA, sGC protein showed a maturational pattern, increasing with GA in preterm ovine fetal mesenteric arteries. PDE5 mRNA was detectable and did not show significant changes after 128-d gestation in the mesenteric arteries. However, PDE5 protein expression increased with gestation, peaking in postnatal mesenteric arteries. As there are no data on PDE5 ontogeny in the mesenteric circulation, it is unclear as to why MA PDE5 protein increases near-term gestation and after birth (Figure 4d). We speculate that this is reflective of the pattern of mesenteric hemodynamics in newborn where the 
intestinal blood flow demonstrates episodic increase only during and immediately after feeds and returns to baseline after nutrient absorption. Elevated MA PDE5 may play a role in decreasing intestinal blood flow after nutrient absorption by breaking down cyclic guanosine monophosphate (cGMP). Maturation of the $\mathrm{NO} / \mathrm{cGMP}$ pathway in pulmonary circulation during the postnatal period is thought to be a key event in the adaptive response after birth. We speculate that a similar process in the mesenteric circulation may influence the gut-adaptive responses after a preterm birth. Figure 5 summarizes the results tabulated by GA.

Understanding the ontogeny of vasomediator mechanisms may give us more insight into the pathophysiology of NEC and help us develop potential therapies for this devastating condition. Endothelial NO is synthesized from the amino acid L-arginine. Small clinical studies have found that preterm neonates who developed NEC had lower levels of serum arginine (32), and L-arginine supplementation appeared to reduce the incidence of NEC in premature infants (33). ET-1 concentration is greater in human preterm intestine that demonstrates histologic evidence of NEC, and arterioles taken from these tissue samples showed increased vasoconstriction which reversed following addition of ET-A antagonist (BQ610) (34). ET-1 blocking agents/antagonists may represent an additional candidate for novel therapy for NEC. However, larger studies are required to fully understand the biology of NEC and effects of these potential therapies before they can be applied clinically.

We acknowledge certain limitations of our study. The number of subjects in each group is small. However, we performed a power analysis of our study using previous published data demonstrating that vasoconstriction to NE is normally distributed with a standard deviation of $401 \mathrm{~g} / \mathrm{g}$ force in 134-d gestation lambs (6). To detect a difference of $800 \mathrm{~g} / \mathrm{g}$ force of contraction between the groups, we needed at least four lambs in each group. We included four to eight lambs in each group in the current study. The Type I error probability associated with this test of null hypothesis is 0.05 with a power of 0.8 .

Vascular reactivity of mesenteric arteries from fetuses of various GAs killed at birth may not be representative of postnatal changes in an extremely preterm infant that survives to late-preterm gestation. We also did not evaluate postnatal lambs prior to their feeds and cannot distinguish the effects of transition at birth (such as oxygenation and intestinal microbiome) from changes induced by enteral feeds. Future studies will aim at separating this effect by studying postnatal lambs with and without enteral nutrition. Finally, changes in mesenteric vascular reactivity in isolated vessel rings can be different from changes observed to in vivo blood flow. We are currently planning studies with a superior mesenteric artery flow probe placed in 134-d gestation fetal lambs in utero $48 \mathrm{~h}$ prior to delivery. We will evaluate the effect of postnatal changes including enteral feeds and other factors that may contribute to perinatal intestinal pathologies such as packed red cell transfusions.

We conclude that MA reactivity changes with GA. Constriction response to catecholamines and endothelin is poor early in gestation but peaks at late-preterm gestation. With advancing gestation, the mesenteric vasculature is primed to vasorelaxation in anticipation of enteral feeding. As previously postulated by Nankervis et al. (2), interventions focused on maintaining the delicate balance favoring vasodilation in the newborn intestinal circulation may prove to be useful in the prevention and treatment of perinatal intestinal diseases such as NEC.

\section{METHODS}

The protocol was approved by the Institutional Animal Care Committee at the University of Buffalo. Time-dated Q-fever seronegative pregnant ewes were purchased from Newlife Pasteur farms (Attica, NY). Normal lamb gestation is 145-147 d. Pregnant ewes were fasted for $12 \mathrm{~h}$ and sedated with intravenous (i.v.) diazepam (0.25$1.5 \mathrm{mg} / \mathrm{kg}$ i.v.) and ketamine ( $4 \mathrm{mg} / \mathrm{kg}$ i.v.), intubated, and placed on $2 \%$ isoflurane anesthesia. Lambs were delivered by C-section at 116-d (previable group), 128-d (early preterm), 134-d (late preterm), and 141-d (near term) GA. Since limited data are available regarding timing of gastrointestinal maturity in lambs, these GAs were chosen based on lung maturity (15-18). The postnatal groups consisted of 2- to 7-d-old lambs delivered vaginally at the farm and established on udder feeds. The lambs were anesthetized with propofol and killed by rapid exsanguination by cardiac puncture, either immediately after birth in the fetal groups or after the in vivo studies were completed in the feeding and transfusion groups. The abdomen was opened and ileum with attached mesentery was excised and placed in warm aerated Krebs solution. Mesenteric arteries from distal ileum were collected for isolated vessel studies and mRNA/protein analysis.

\section{Isolated Vessel Studies}

The small mesenteric arteries (0.5- to $1-\mathrm{mm}$ diameter) adjacent to the ileum were dissected and washed in Krebs solution (composition in mM: $\mathrm{NaCl} 119, \mathrm{KCl} 5.4, \mathrm{CaCl}_{2} 2.5, \mathrm{KH}_{2} \mathrm{PO}_{4} 0.6, \mathrm{MgSO}_{4} 1.2$, $\mathrm{NaHCO}_{3} 25$, and glucose 11.7) in vessel baths aerated with $21 \% \mathrm{O}_{2}$ and $6 \% \mathrm{CO}_{2}$ to give an estimated $\mathrm{pH}$ of 7.4 , as described previously (35). The samples were mounted and stretched in these baths, and the isometric tension was measured. A continuous recording of isometric force generation was obtained by tying each vessel ring to a force displacement transducer (model UC2, Statham Instruments, Hato Rey, Puerto Rico) that was connected to a recorder (Gould Instrument Systems, Valley View, OH).

Mesenteric arterial rings were pretreated with propranolol $\left(10^{-6} \mathrm{M}\right)$ to block the beta-adrenergic effects $(36,37)$ and constricted with increasing titrations from $10^{-8}$ to $10^{-5} \mathrm{M}$ of the NE. Other vessels were constricted with ET-1 $\left(10^{-10}\right.$ to $\left.10^{-7} \mathrm{M}\right)$. A few MA rings were pretreated with LNA $\left(10^{-3} \mathrm{M}\right)$, an antagonist of eNOS, to reflect baseline eNOS activity prior to constriction with NE. Response to LNA was calculated as (constriction to LNA + NE $10^{-5} \mathrm{M}$ - constriction to NE $10^{-5} \mathrm{M}$ ) and expressed as a percentage of NE constriction. To study relaxation responses, $\mathrm{MA}$ rings were preconstricted with an $\mathrm{EC}_{50}$ concentration of NE and relaxed with increasing concentrations of SNAP $\left(10^{-8}\right.$ to $\left.10^{-5} \mathrm{M}\right)$ or A23187 $\left(10^{-8}\right.$ to $\left.10^{-6} \mathrm{M}\right)$. Finally, the vessel rings were washed multiple times with Krebs solution. Maximal contractile response to $118 \mathrm{mmol} / \mathrm{l}$ of $\mathrm{KCl}$ was obtained. Wet tissue weights were obtained at the end of each experiment, and constriction responses were normalized to tissue weight.

Data were plotted as force of constriction per unit of tissue weight (and expressed as grams of force per gram of weight) against increasing concentrations of the vasoconstrictor agent for the constriction curves and as a percentage of $\mathrm{EC}_{50}$ constriction against increasing concentrations of the vasodilator agent for the relaxation curves. All drugs were purchased from Sigma Aldrich (St. Louis, MO). SNAP was dissolved in a small quantity of dimethylsulfoxide and subsequently in water. LNA was dissolved in Krebs solution using sonication. All other drugs were dissolved in water. Experiments were conducted in a dark room as LNA is sensitive to light.

\section{RNA Isolation}

Freshly excised MA tissue adjacent to the ileum was flash frozen in liquid nitrogen and stored at $-80{ }^{\circ} \mathrm{C}$ until ready for use. Tissues were 
weighed and homogenized on dry ice. RNA was isolated using RNeasy Mini kit (Qiagen, Valencia, CA) with on-column DNAase digestion per manufacturer's protocol. RNA integrity was assessed using Experion Automated Electrophoresis System (BioRad, Hercules, CA). The RQI (RNA Quality Indicator) for all samples analyzed was $>6.8$.

\section{Quantitative Reverse-Transcriptase PCR}

To assess genomic DNA contamination, a no-reverse transcriptase PCR reaction was performed on the native RNA. RNA (500 ng) was reverse transcribed using iScript cDNA synthesis kit (BioRAD). Three reference genes for normalization were chosen using GeNorm (Biogazelle, Zwijnaarde, Belgium)_ribosomal protein subunits 2 (rps2) and 26 (rps26) and adenosine triphosphate synthetase (ATPsynth). PCR primers for genes of interest-eNOS, sGCB1, and PDE5a-have been described previously (32). ETRA and ADRA1A were chosen using Primer-BLAST Primer Design tool (National Center for Biotechnology Information, Bethesda, MD). All products were verified for appropriate size by gel electrophoresis and sequenced to confirm their identity. PCR was performed in a MyiQ thermal cycler (BioRad) at $95^{\circ} \mathrm{C}$ for $4 \mathrm{~min}$, then 40 cycles at $95^{\circ} \mathrm{C}$ for $30 \mathrm{~s}$, and finally at $60^{\circ} \mathrm{C}$ for $1 \mathrm{~min}$. PCR for PDE5a was similarly performed but with an annealing temperature of $46^{\circ} \mathrm{C}$, as described previously (32). Relative expression was normalized to reference genes using $2(-\Delta \Delta C(T))$ method (33). Samples were assayed in duplicate and analyzed. Results were expressed as fold change compared with the values obtained from postnatal lambs.

\section{Western Blot Analysis}

Mesenteric arteries of $0.5 \mathrm{~mm}$ diameter were dissected out and flash frozen in liquid nitrogen and stored at $-80{ }^{\circ} \mathrm{C}$ until use. Tissues were homogenized in liquid nitrogen using a mortar and pestle, and protein was isolated using PARIS kit (Ambion Life Technologies, Grand Island, NY) per manufacturer's protocol. Briefly, $60 \mathrm{mg}$ of tissue was processed and supplemented with protease inhibitor cocktail (Sigma). Protein concentration was determined using protein assay (BioRad). Total protein $(60 \mu \mathrm{g})$ was separated on $4-20 \%$ SDS-polyacrylamide gels (BioRad) and transferred to nitrocellulose membrane (BioRad). The membranes were then cut to allow simultaneous probing with antibody of interest and normalization protein.

Membranes were blocked in tris-buffered saline Tween supplemented with $5 \%$ nonfat dry milk for $1 \mathrm{~h}$ and incubated overnight at $4{ }^{\circ} \mathrm{C}$ with primary antibody as follows: mouse anti PDE5 (BD Transduction, San Jose, CA) at 1:333, mouse anti eNOS (BD Transduction) at 1:1000, anti-rabbit sGC $\beta 1$ (Cayman Chemical, Ann Arbor, MI) at 1:500, and mouse anti actin (Sigma) at 1:2000 in blocking buffer. Blots were washed three times in blocking buffer and incubated for $1 \mathrm{~h}$ at room temperature with appropriate horseradish peroxidase-conjugated secondary antibody (Cell Signaling Technology, Danvers, MA) at 1:1000 in blocking buffer. Blots were washed four times with blocking buffer and developed using ECL Western Blotting Substrate (Pierce, Rockford, IL) according to manufacturer's protocol. Blots were visualized using a Fuji intelligent Imager and Fuji LAS-1000 software and analyzed using FlourChem 8900 software Alpha Innotech (San Leandro, CA). Blots for each protein of interest (eNOS, sGC, and PDE5) and the corresponding actin were visualized simultaneously.

\section{Enzyme-Linked Immunosorbent Assay}

Arteries were dissected out and flash frozen in liquid nitrogen and stored at $-80^{\circ} \mathrm{C}$ until use. Tissues were homogenized in liquid nitrogen using a mortar and pestle, and protein was isolated using PARIS kit (Ambion Life Technologies) per manufacturer's protocol. Briefly, $60 \mathrm{mg}$ of tissue was processed and supplemented with protease inhibitor cocktail (Sigma). Protein concentration was determined using protein assay (BioRad).

Enzyme-linked immunosorbent assays for both alphala and ETRA (MyBiosource, San Diego, CA) were performed according to manufacturer's protocol. Samples were assayed in duplicate. Results were normalized to total protein.

\section{Statistical Analysis}

Comparison between GA groups in vascular reactivity was analyzed by ANOVA repeated measures and ANOVA with Fisher's protected least significant difference (PLSD) post hoc testing using IBM SPSS Statistics software for Windows, Version 22.0. Armonk, NY: IBM Corp. RT-PCR and western blot data were analyzed by ANOVA with Fisher's PLSD post hoc testing. Data are presented as mean \pm SEM. Significance was accepted at $P<0.05$.

\section{STATEMENT OF FINANCIAL SUPPORT}

This study was funded by 1RO\#HD060138-01 (S.L.), 1R01HD072929 (S.L.), National Institutes of Health-Eunice Kennedy Shriver National Institute of Child Health and Human Development (Bethesda, MD) and Buswell fellowship (J.N.); State University of New York at Buffalo (Buffalo, NY); and the Department of Pediatrics, University at Buffalo (Buffalo, NY).

Disclosure: No conflicts of interest, financial or otherwise, are declared by the authors.

\section{REFERENCES}

1. Coombs RC, Morgan ME, Durbin GM, Booth IW, McNeish AS. Doppler assessment of human neonatal gut blood flow velocities: postnatal adaptation and response to feeds. J Pediatr Gastroenterol Nutr 1992;15:6-12.

2. Nankervis CA, Giannone PJ, Reber KM. The neonatal intestinal vasculature: contributing factors to necrotizing enterocolitis. Semin Perinatol 2008;32:83-91.

3. Patel RM, Kandefer S, Walsh MC, et al.; Eunice Kennedy Shriver National Institute of Child Health and Human Development Neonatal Research Network. Causes and timing of death in extremely premature infants from 2000 through 2011. N Engl J Med 2015;372:331-40.

4. McGrady GA, Rettig PJ, Istre GR, Jason JM, Holman RC, Evatt BL. An outbreak of necrotizing enterocolitis. Association with transfusions of packed red blood cells. Am J Epidemiol 1987;126:1165-72.

5. Mohamed A, Shah PS. Transfusion associated necrotizing enterocolitis: a meta-analysis of observational data. Pediatrics 2012;129:529-40.

6. Nair J, Gugino SF, Nielsen LC, et al. Packed red cell transfusions alter mesenteric arterial reactivity and nitric oxide pathway in preterm lambs. Pediatr Res 2013;74:652-7.

7. Upperman JS, Potoka D, Grishin A, Hackam D, Zamora R, Ford HR. Mechanisms of nitric oxide-mediated intestinal barrier failure in necrotizing enterocolitis. Semin Pediatr Surg 2005;14:159-66.

8. La Gamma EF, Feldman A, Mintzer J, Lakshminrusimha S, Alpan G. Red blood cell storage in transfusion-related acute gut injury. NeoReviews 2015;16:e420-e30.

9. Nankervis CA, Nowicki PT. Role of nitric oxide in regulation of vascular resistance in postnatal intestine. Am J Physiol 1995;268:G949-58.

10. Reber KM, Su BY, Clark KR, Pohlman DL, Miller CE, Nowicki PT. Developmental expression of eNOS in postnatal swine mesenteric artery. Am J Physiol Gastrointest Liver Physiol 2002;283:G1328-35.

11. Moonen RM, Villamor E. Developmental changes in mesenteric artery reactivity in embryonic and newly hatched chicks. J Comp Physiol B 2011;181:1063-73.

12. Clark DA, Munshi UK. Development of the gastrointestinal circulation in the fetus and newborn. In: Polin RA, Fox WW, Abman SH, eds. Fetal and Neonatal Physiology. Philadelphia, PA: Saunders, 2011:773-6.

13. Fronek K, Stahlgren LH. Systemic and regional hemodynamic changes during food intake and digestion in nonanesthetized dogs. Circ Res 1968;23:687-92.

14. Vatner SF, Franklin D, Van Citters RL. Mesenteric vasoactivity associated with eating and digestion in the conscious dog. Am J Physiol 1970;219: 170-4.

15. Dawes GS. Foetal and Neonatal Physiology-A Comparative Study of the Changes at Birth. Chicago, IL: Year Book Medical Publishers, 1968.

16. Zoetis T, Hurtt ME. Species comparison of lung development. Birth Defects Res B Dev Reprod Toxicol 2003;68:121-4.

17. Pitt BR, Brookens MA, Steve AR, et al. Expression of pulmonary metallothionein genes in late gestational lambs. Pediatr Res 1992;32:424-30.

18. Strang LB. Neonatal Respiration-Physiological and Clinical Studies. London: Blackwell Scientific Publications, 1977.

19. Sangild PT. Gut responses to enteral nutrition in preterm infants and animals. Exp Biol Med (Maywood) 2006;231:1695-711. 


\section{Articles | Nairetal.}

20. Bisset WM, Watt JB, Rivers RP, Milla PJ. Ontogeny of fasting small intestinal motor activity in the human infant. Gut 1988;29:483-8.

21. Bueno L, Ruckebusch Y. Perinatal development of intestinal myoelectrical activity in dogs and sheep. Am J Physiol 1979;237:E61-7.

22. Martí D, Miquel R, Ziani K, et al. Correlation between mRNA levels and functional role of alpha1-adrenoceptor subtypes in arteries: evidence of alpha1 $\mathrm{L}$ as a functional isoform of the alpha1 A-adrenoceptor. Am J Physiol Heart Circ Physiol 2005;289:H1923-32.

23. Martínez-Salas SG, Campos-Peralta JM, Pares-Hipolito J, GallardoOrtíz IA, Ibarra M, Villalobos-Molina R. Alpha1A-adrenoceptors predominate in the control of blood pressure in mouse mesenteric vascular bed. Auton Autacoid Pharmacol 2007;27:137-42.

24. Rudner XL, Berkowitz DE, Booth JV, et al. Subtype specific regulation of human vascular alpha(1)-adrenergic receptors by vessel bed and age. Circulation 1999;100:2336-43.

25. Haynes WG, Webb DJ. Contribution of endogenous generation of endothelin-1 to basal vascular tone. Lancet 1994;344:852-4.

26. Nankervis CA, Nowicki PT. Role of endothelin-1 in regulation of the postnatal intestinal circulation. Am J Physiol Gastrointest Liver Physiol 2000;278:G367-75.

27. Fan WQ, Smolich JJ, Wild J, Yu VY, Walker AM. Major vasodilator role for nitric oxide in the gastrointestinal circulation of the mid-gestation fetal lamb. Pediatr Res 1998;44:344-50.

28. Fan WQ, Smolich JJ, Wild J, Yu VY, Walker AM. Nitric oxide modulates regional blood flow differences in the fetal gastrointestinal tract. Am J Physiol 1996;271:G598-604.
29. González-Rivera R, Culverhouse RC, Hamvas A, Tarr PI, Warner BB. The age of necrotizing enterocolitis onset: an application of Sartwell's incubation period model. J Perinatol 2011;31:519-23.

30. Llanos AR, Moss ME, Pinzòn MC, Dye T, Sinkin RA, Kendig JW. Epidemiology of neonatal necrotising enterocolitis: a population-based study. Paediatr Perinat Epidemiol 2002;16:342-9.

31. Neu J. Neonatal necrotizing enterocolitis: an update. Acta Paediatr Suppl 2005;94:100-5.

32. Becker RM, Wu G, Galanko JA, et al. Reduced serum amino acid concentrations in infants with necrotizing enterocolitis. J Pediatr 2000; 137:785-93.

33. Amin HJ, Zamora SA, McMillan DD, et al. Arginine supplementation prevents necrotizing enterocolitis in the premature infant. J Pediatr 2002;140:425-31.

34. Nowicki PT, Dunaway DJ, Nankervis CA, et al. Endothelin-1 in human intestine resected for necrotizing enterocolitis. J Pediatr 2005;146: 805-10.

35. Lakshminrusimha S, Russell JA, Steinhorn RH, et al. Pulmonary arterial contractility in neonatal lambs increases with $100 \%$ oxygen resuscitation. Pediatr Res 2006;59:137-41.

36. Schindler MB, Hislop AA, Haworth SG. Postnatal changes in response to norepinephrine in the normal and pulmonary hypertensive lung. Am J Respir Crit Care Med 2004;170:641-6.

37. Irish MS, Glick PL, Russell J, et al. Contractile properties of intralobar pulmonary arteries and veins in the fetal lamb model of congenital diaphragmatic hernia. J Pediatr Surg 1998;33:921-8. 